\title{
Synthesis of Modified Polycarboxylate and Its Application in Ultra-High Performance Concrete
}

\author{
Shuncheng Xiang, Yansheng Tan and Yingli Gao* \\ School of Traffic and Transportation Engineering, Changsha University of Science and Technology, Changsha, China
}

Modified polyurethane prepolymer was prepared using the segmental synthesis method. Then, pectiniform polycarboxylate was synthesized at normal temperature in the complex initiation system of $\mathrm{H}_{2} \mathrm{O}_{2}$, APS, sodium bisulfite, $\mathrm{Vc}$, and Rongalit according to the free radical polymerization reaction mechanism, using TPEG, AA, and PEG as raw materials and TGA as the chain transfer agent. Compared with commercial Sika polycarboxylate, its flowability, strength, drying shrinkage, and auto-shrinkage were studied. The experimental results show that the synthesized polycarboxylate could be better dispersed. Adding silica fume can enhance the compressive strength of ultra-high performance concrete (UHPC), while slag may decline its strength. By incorporating slag and silica fume, the drying shrinkage of UHPC was reduced, but its auto-shrinkage was increased.

Edited by: Dong Xiang, Southwest Petroleum University

China

Reviewed by: Sicong $\mathrm{Hu}$,

Nanchang University, China Hongxia Gao, Hunan University, China Jiake Zhang,

Tongji University, China

*Correspondence: Yingli Gao yingligao@126.com

Specialty section:

This article was submitted to Polymeric and Composite Materials,

a section of the journal

Frontiers in Materials

Received: 15 June 2021

Accepted: 30 June 2021

Published: 09 August 2021

Citation:

Xiang S, Tan Y and Gao Y (2021)

Synthesis of Modified Polycarboxylate and Its Application in UItra-High

Performance Concrete.

Front. Mater. 8:725242.

doi: $10.3389 /$ fmats.2021.725242
Keywords: polycarboxylate, synthesis at indoor temperature, UHPC, application, interaction

\section{INTRODUCTION}

Multifunctional polycarboxylate has been developed rapidly over the decades. Polycarboxylate has functions such as slump protection, coagulation control, and shrinkage reduction. By adding polycarboxylate, the force between Portland cement particles and the physicochemical properties of their solid-liquid interface are changed, thus affecting the flowability of cement paste (Andersen et al., 1987; LI et al., 2005). However, at present, the synthesis of polycarboxylate is usually carried out by heating, with synthesis temperature between 60 and $90^{\circ} \mathrm{C}$. However, preparation of polycarboxylate at indoor temperature has become a development trend of superplasticizer industry (Shang et al., 2009).

With the birth of polycarboxylate, preparing concrete mixtures with low water-to-binder ratio and high flowability becomes possible. Designing appropriate polycarboxylate can not only reduce the water demand of ultra-high performance concrete (UHPC) but also promote condensation hardening and strength development (Shi, 2009; Shi and He, 2010). According to the supersuperposition effect of component properties, using two or more mineral admixtures to the compound can not only achieve the complementary advantages and further improve the comprehensive performance but also give full play to the excellent performance of composite mineral admixtures in view of the problem that the quality of mineral admixtures fluctuates greatly in China and affects quality control in the concrete production process (AITCIN, 2003).

In this paper, polyurethane-modified polycarboxylate was prepared at indoor temperature by controlling the molar ratio of acrylic acid to macromonomer. And its application in ultra-high performance concrete was studied by comparing with Sika high-performance polycarboxylate, which would be very valuable for practical engineering applications. 
TABLE 1 | Chemical constitution of PI 42.5 Portland cement, slag, fly ash, and silica fume $\mathrm{w} / \%$.

\begin{tabular}{lccccc} 
Material & \multicolumn{5}{c}{ Chemical constitution $\mathbf{w} / \%$} \\
\cline { 2 - 6 } & $\mathbf{S i O}_{\mathbf{2}}$ & $\mathbf{A l}_{\mathbf{2}} \mathbf{O}_{\mathbf{3}}$ & $\mathbf{F e}_{\mathbf{2}} \mathbf{O}_{\mathbf{3}}$ & $\mathbf{C a O}$ & $\mathbf{M g O}$ \\
\hline Cement & 25.26 & 6.38 & 4.05 & 64.67 & 2.68 \\
Slag & 33 & 13.91 & 0.82 & 39.11 & 10.04 \\
Silica fume & 90.82 & 1.03 & 1.50 & 0.45 & 0.83
\end{tabular}

\section{EXPERIMENT}

\section{Raw Materials}

PI 42.5 cement, mineral powder, and silica fume were adopted as raw materials, as shown in Table 1. The average particle size of PI 42.5 cement, mineral powder, and silica fume is $36.96,20.30$, and $0.22 \mu \mathrm{m}$, respectively. The molecular structure of commercial Sika high-performance polycarboxylate is shown in Figure 1.

Isophorone diisocyanate, hydroxyl-terminated silicone, polyether glycol, N-methylpyrrolidone, 1,4-butanediol, dimethylolpropionic acid, and prenyl alcohol polyoxyethylene ether (TPEG) were used for synthesis; the pure acrylic acid (AA), thioglycolic acid, p-toluenesulfonic acid, polyethylene glycol-200 (PEG-200), ascorbic acid $(\mathrm{Vc})$, hydrogen peroxide, dibutyltin dilaurate, ammonium persulfate, and deionized water were analyzed.

\section{Synthesis of Side Chain}

During the synthesis, alcohol and amine compounds and multifunctional groups were introduced into the main chain of polycarboxylate molecules, so as to bring about more short branches, promote the alternating distribution of long polyether branches and short branches of chain extenders of alcohol and amine compounds, and increase the dispersibility and adaptability of the superplasticizer.

22.2 $\mathrm{g}$ isophorone diisocyanate was placed in a three-necked flask, polyethylene glycol 1000 containing dibutyltin dilaurate (Nmethylpyrrolidone solution with $0.2 \mathrm{~g}$ dibutyltin dilaurate), and dimethylolpropionic acid in $25 \mathrm{~g}$ polyethylene glycol 1000 (3.35 g dimethylolpropionic acid dissolved in $5 \mathrm{ml} \mathrm{N}$-methylpyrrolidone) was added dropwise in turn with a dropping funnel, and then $50 \mathrm{~g}$ water was added. The mixture was heated to $70^{\circ} \mathrm{C}$ and kept warm. Then, the mixed solution of hydroxyl-terminated polysiloxane and 1,4butanediol ( $9 \mathrm{~g}$ of hydroxyl-terminated polysiloxane mixed with $3 \mathrm{~g}$ of 1,4-butanediol), $2.5 \mathrm{~g}$ of ethylenediamine, and $1.5 \mathrm{~g}$ of sodium dodecylbenzenesulfonate were added dropwise while stirring before feeding. When the free-NCO content in the mixed solution was detected to be $16 \%$, heating was stopped to obtain the polyurethane prepolymer. The principle of side chain reaction was shown in Figure 2.

\section{Preparation of Polycarboxylate (M-PCE)}

To ensure the equal molar concentration of double bonds in the system, the concentration of free radicals and molecular weight regulators was controlled, and the molar ratio of acrylic acid to TPEG was adjusted. TPEG (120 g), purified water $(80 \mathrm{ml})$, and PEG-200 (10 g) were put into a $250 \mathrm{ml}$ four-necked flask. After fully stirring the mixed solution, $0.1 \mathrm{~g}$ dibutyltin dilaurate, $1.2 \mathrm{~g}$ of

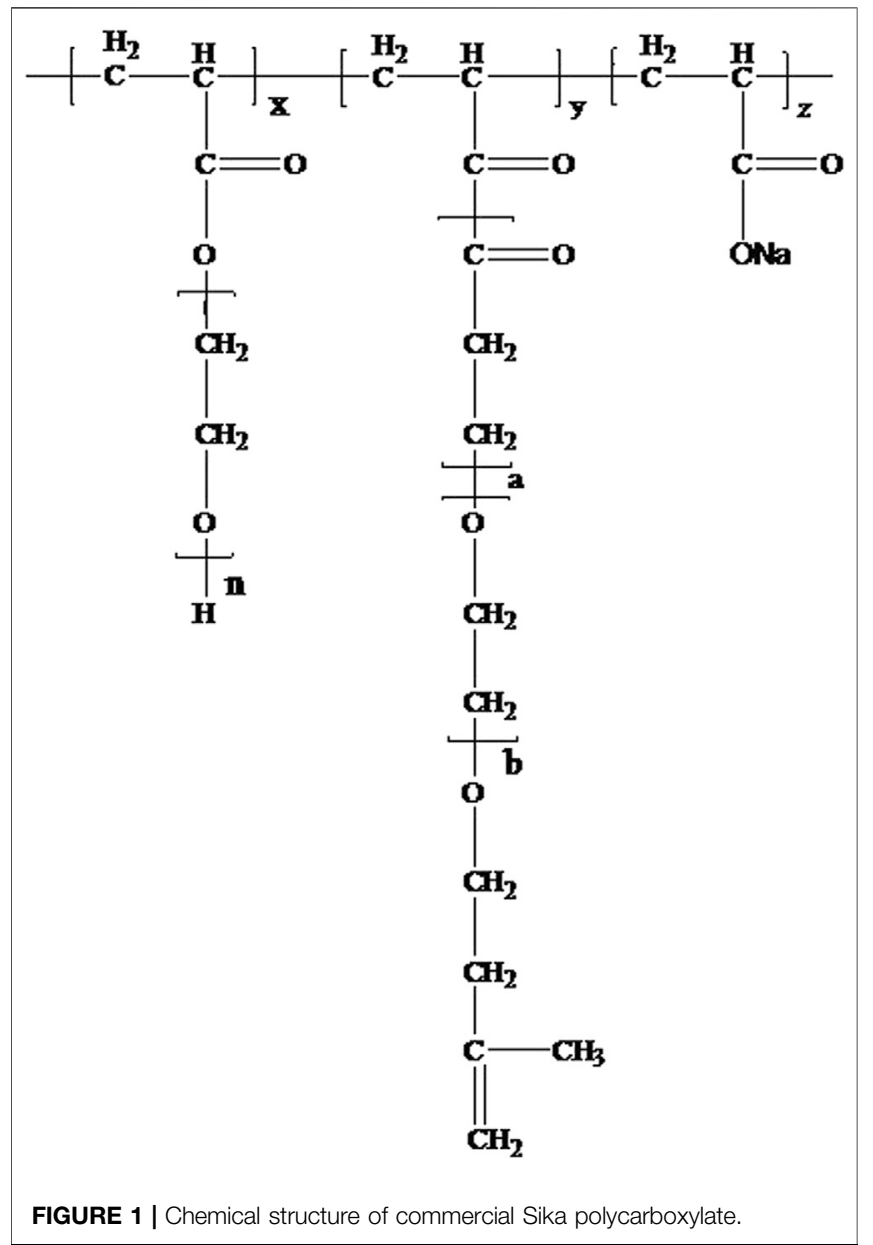

p-toluenesulfonic acid, and 30\% hydrogen peroxide were added. $\mathrm{A}$ and $\mathrm{B}$ solutions were prepared for later use.

Component A (acrylic acid + sodium bisulfite, Vc, or sodium formaldehyde sulfoxylate).

Component B (thioglycolic acid + ammonium persulfate).

A peristaltic pump was used to drip components $A$ and $B$ into the beaker at the rate of $2 \mathrm{ml} / \mathrm{min}$, which lasted for $2.5 \mathrm{~h}$. After that, the mixed solution was kept warm for a period of time, and the $\mathrm{pH}$ value was adjusted to $6-7$ with $\mathrm{NaOH}$ to obtain mother liquor of polycarboxylate (M-PCE). The structure of synthesized $\mathrm{M}-\mathrm{PCE}$ was shown in Figure 3.

\section{Mortar Water-Reduction Rate Test}

In view of GB/T8077-2012 Test Method for Homogeneity of Concrete Admixtures, the water reduction rate of polycarboxylate mortar is tested using the following formula:

$$
\text { Mortar water reduction rate }=\frac{M_{0}-M_{1}}{M_{0}} \times 100 \%
$$

Here, $M_{0}$ is the water consumption of benchmark mortar flowability $(\mathrm{mm})$ and $M_{1}$ is the water consumption when the flowability of mortar with admixture reaches $180 \pm 5 \mathrm{~mm}$. 


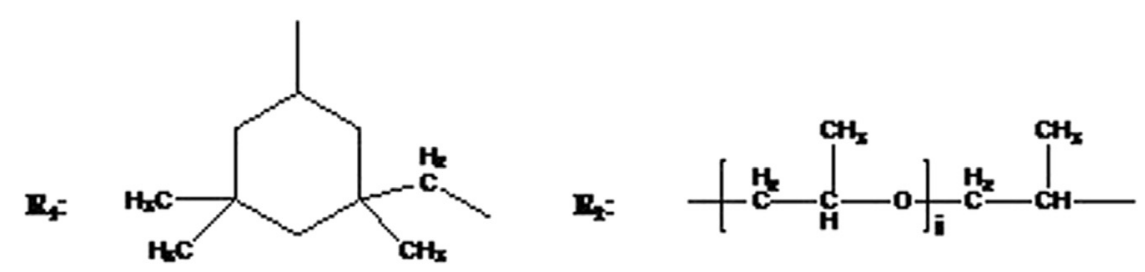<smiles>CC(C)(C)[Si](C)(C)O[Si](C)(C)C</smiles>

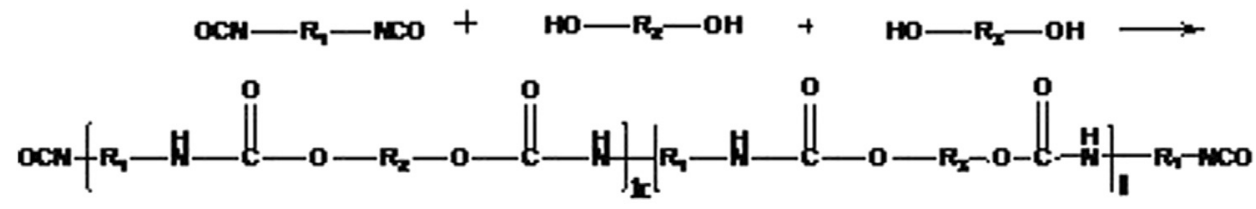

natiod as OCN-R4-NCOI

Chain extension:
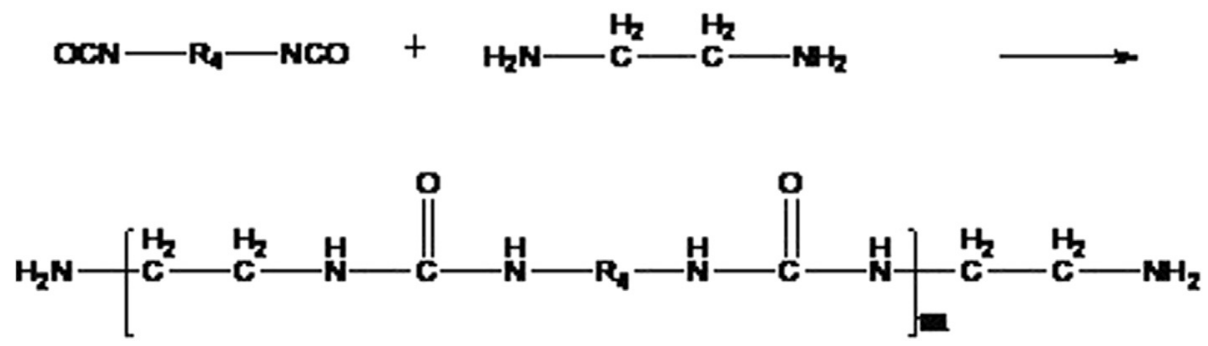

FIGURE 2 | Principle of side chain reaction and its molecular structure.

\begin{tabular}{lccc}
\hline \multicolumn{2}{l}{ TABLE 2 } & Binder constitution of UHPC. & \\
\hline No. & Portland cement (\%) & Silica fume (\%) & Slag (\%) \\
\hline N1 & 100 & 0 & 0 \\
N2 & 85 & 15 & 0 \\
N3 & 59.9 & 15 & 25.1 \\
N4 & 72.2 & 11.1 & 16.7 \\
N5 & 70 & 30 & 0 \\
N6 & 58.3 & 16.7 & 25 \\
N7 & 40 & 20 & 40
\end{tabular}

\section{Mix Proportion of UHPC}

The content of polycarboxylate is $2 \%$ (mass ratio) of cementitious components, the water-to-binder ratio of ultra-high performance concrete is 0.18 , and the sand-to-binder ratio is 1.0. Table 2 shows the mixture ratios.

\section{Flowability}

According to the standard GB/T2419-2005 "Method for Measuring Fluidity of Cement Mortar," fine sand below $2.36 \mathrm{~mm}$ was selected, the mass of cementitious material was $200 \mathrm{~g}$, the sand-to-cement ratio was 1:1, the water-to-binder ratio was 0.18 , and the polycarboxylate mother liquor content was $2 \%$, then, the flowability of mortar was tested.

\section{Strength}

In the free shrinkage test, reference cement and standard sand were used, with the ratio of sand to cement of 1:1. The flowability of 


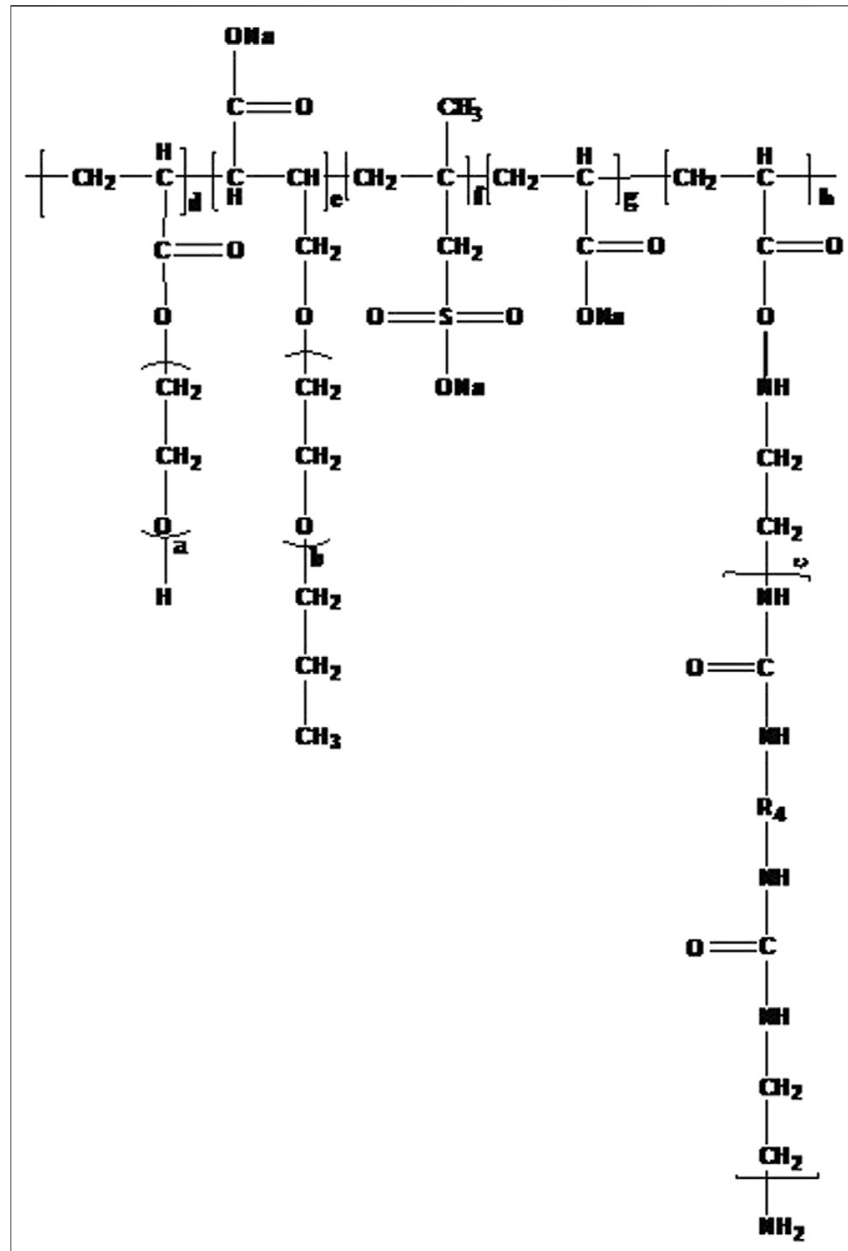

FIGURE 3 | Structure of synthesized modified polycarboxylate (M-PCE).

cement mortar was higher than $140 \mathrm{~mm}$, and a set of $40 \times 40 \times$ $160 \mathrm{~mm}$ specimens was reported. The test molds were triple molds and were filled and maintained for $24 \mathrm{~h}$. The temperature of the curing box was controlled to be $20^{\circ} \mathrm{C} \pm 1^{\circ} \mathrm{C}$, and the relative humidity was equal to or higher than $90 \%$. Then, the mold was transferred to the steam curing room. The temperature in the drying room was $20 \pm 3^{\circ} \mathrm{C}$. Then, the strength at the 1 st, the $3 \mathrm{rd}$, the 7 th, the 14 th, and the 28 th day was tested.

\section{Drying Shrinkage}

In view of JC/T603-2004 "Test Method for Drying Shrinkage of Cement Mortar," a group of $25 \times 25 \times 280 \mathrm{~mm}$ specimens should be formed in the drying shrinkage test of cement mortar, and the specimens should be demolded after being cured for $24 \pm 1 \mathrm{~h}$ from the time of adding water. Then, the length of the test at the 1 st day, 3rd day, 7th day, 14th day, 21st day, 28th day, 56th day, and 90th day was measured. The result was calculated according to the following formula, accurate to $0.001 \%$ :

$$
S_{n}=\frac{\left(L_{0}-L_{28}\right) \times 100}{280},
$$

where $\mathrm{Sn}$ is the drying shrinkage rate of the cement mortar specimen at the nth day (\%); $\mathrm{L}_{0}$ is the initial measurement reading $(\mathrm{mm}) ; \mathrm{L}_{28}$ is the measured reading at the 28 th day $(\mathrm{mm})$; and 280 is the effective length of the specimen $(\mathrm{mm})$.

\section{Auto-Shrinkage}

The auto-shrinkage of mortar in self-compacting cement mortar was measured with the combination of a bellow and a noncontact probe. The bellow has an inner diameter of $20 \mathrm{~mm}$ and a length of $340 \pm 5 \mathrm{~mm}$. The cement mortar flowability was higher than $140 \mathrm{~mm}$, and the auto-shrinkage of cement mortar was continuously measured for $72 \mathrm{~h}$.

\section{RESULTS AND DISCUSSION}

\section{Water Reduction Rate of Mortar}

The water consumption of benchmark mortar without superplasticizer was $93.7 \mathrm{~g}$, which was 186 and $175 \mathrm{~mm}$ with an average of about $180 \mathrm{~mm}$ after rest. The experimental results are shown in Table 3.

The water reduction rate of mortar of M-PCE was similar to that of Sika. In terms of the molecular structure, the dispersing group of Sika was mainly a long-chain alkyl macromonomer. However, the dispersing ability of M-PCE was enhanced by the strong chemical bond of silicone groups in M-PCE and silicate phase (Jones et al., 1995). Due to its chemical structure, M-PCE has longer side chains than PCE, indicating good steric hindrance (Levi et al., 2002). Therefore, the dispersibility of M-PCE in cement is also excellent, which is consistent with the results of Kong et al. (Thompson et al., 1997) Silicone chains provide spatial repulsion between cement particles in some way, exerting dispersing effect on cement slurry. The anchoring ability of silicone groups has been confirmed by the enhanced adsorption behavior of silane-modified polycarboxylate in cement slurry (Kagi and Ren, 1995).

\section{Flowability}

The flowability of UHPC under the cement mortar-silica fume-mineral powder gelatinization system is shown in Table 4.

According to Table 4, the flowability of M-PCE was better than that of Sika under the same conditions, indicating that

TABLE 3 | Water reduction rate of polycarboxylate in mortar.

\begin{tabular}{|c|c|c|c|c|c|}
\hline Polycarboxylate & $\begin{array}{c}\text { Cement mortar } \\
\text { (g) }\end{array}$ & $\begin{array}{l}\text { Standard sand } \\
\text { (g) }\end{array}$ & $\begin{array}{l}\text { Water consumption } \\
\qquad M_{1}(\mathrm{~g})\end{array}$ & Flowability & $\begin{array}{c}\text { Water reduction } \\
\text { rate }(\%)\end{array}$ \\
\hline M-PCE & 150 & 450 & 51.8 & $180 \mathrm{~mm}, 183 \mathrm{~mm}$ & 44.7 \\
\hline Sika & 150 & 450 & 52.3 & $180 \mathrm{~mm}, 185 \mathrm{~mm}$ & 44.2 \\
\hline
\end{tabular}


TABLE 4 | Initial flowability of UHPC (mm).

\begin{tabular}{lccccccc}
\hline Polycarboxylate & \multicolumn{7}{c}{ Number } \\
\cline { 2 - 8 } & N1 & N2 & N3 & N4 & N5 & N6 & N7 \\
\hline M-PCE & 165 & 119 & 192 & 160 & 172 & 183 & 232 \\
Sika & 163 & 156 & 106 & 146 & 151 & 178 & 102
\end{tabular}

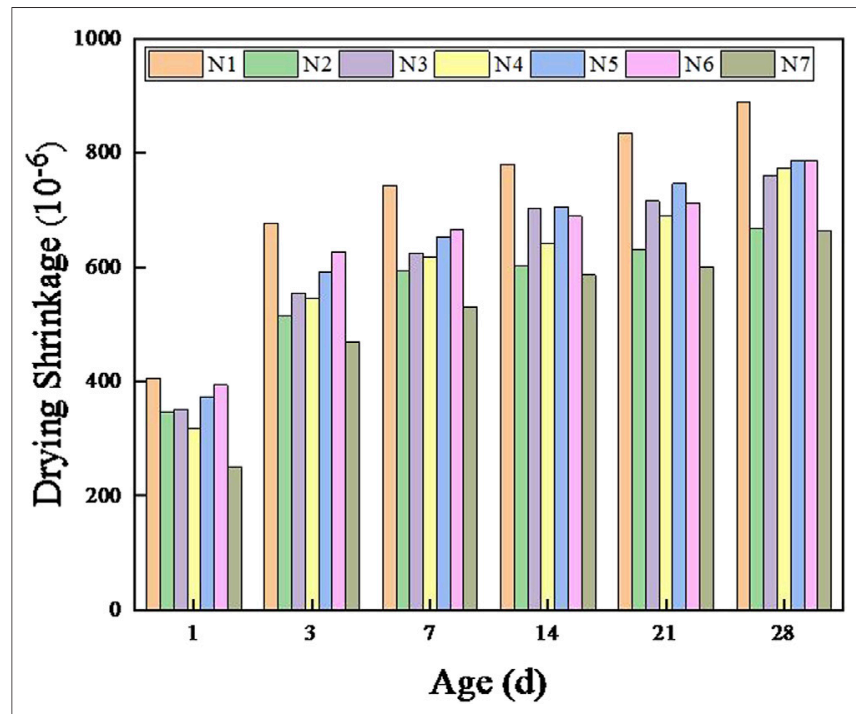

FIGURE 4 | Effect of M-PCE on drying shrinkage of UHPC.

M-PCE had better dispersion than Sika. In addition, the flowability of ultra-high performance concrete increased from 119 to $172 \mathrm{~mm}$ as silica fume content increased from 0 to $30 \%$. However, when the amount of silica fume was too large, the flowability of concrete decreased. A large amount of superplasticizer will be adsorbed on the surface of silica fume with small particle size (Ganesh and Surya, 1995; Khatri et al., 1995). Under the action of superplasticizer, silica fume, as ultrafine particles, disperses cement particles and releases more free water (Duval and Kadri, 1998). For ordinary concrete, the dosage of silica fume is lower than $10 \%$. For high-strength concrete, the dosage of silica fume should be increased to $10 \%$ (Khayat et al., 1993). UHPC silica fume consumption is usually lower than $15 \%$ (Mazloom et al., 2004). For UHPC studied in this paper, if the amount of silica fume is over $30 \%$, it will make concrete extremely viscous, reducing the flowability of concrete.

The specific surface area of mineral powder is larger than that of cement. Therefore, mineral powder significantly affects the flowability of UHPC. When the amount of mineral powder exceeds $40 \%$, the flowability of UHPC is less than $140 \mathrm{~mm}$.

\section{Strength}

Under the cement mortar-silica fume-mineral powder gelatinization system, M-PCE and Sika polycarboxylate were, respectively, used to prepare UHPC.

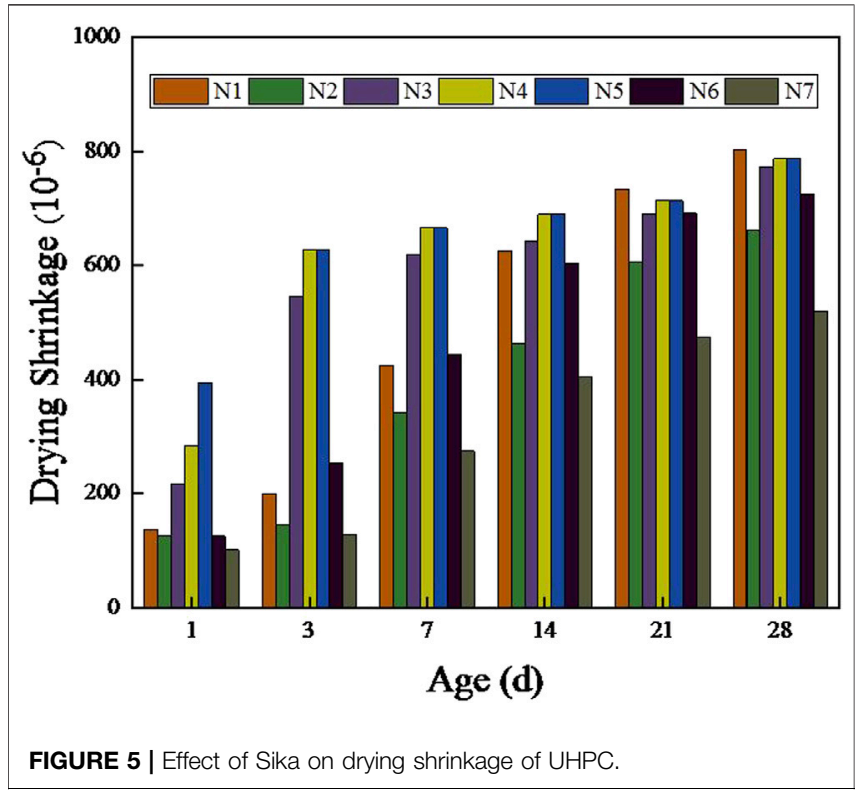

TABLE 5 | Compressive strength of UHPC (M-PCE).

Number

Compressive strength (MPa)

\begin{tabular}{lcccc}
\cline { 2 - 5 } & 3d & $\mathbf{7 d}$ & $\mathbf{1 4 d}$ & $\mathbf{2 8 d}$ \\
\hline N1 & 73.4 & 81.6 & 92.9 & 97.4 \\
N2 & 76.3 & 84.9 & 96.9 & 115.5 \\
N3 & 71.0 & 83.7 & 90.4 & 100.9 \\
N4 & 74.5 & 80.4 & 99.7 & 116.3 \\
N5 & 72.7 & 81.0 & 93.2 & 101.4 \\
N6 & 75.5 & 81.4 & 88.9 & 99.5 \\
N7 & 63.6 & 72.9 & 89.4 & 103.6 \\
\hline
\end{tabular}

As can be seen from Table 4, UHPC prepared with the two different superplasticizers had little difference in compressive strength. Table 5 shows that, with the increase of silica fume dosage, the early compressive strength of UHPC increased. After the amount of silica fume exceeds $25 \%$, the increment of strength slows down. When the amount of silica fume increased from 0 to $15 \%$, the 28 -day strength of concrete rose from 92.5 to $117.4 \mathrm{MPa}$. Therefore, silica fume could improve the compressive strength of ultra-high strength concrete. It is worth noting that, at the dosage of silica fume lower than $15 \%$, the 28 -day compressive strength of UHPC increased with the dosage of silica fume. Table 6 also shows the same trend. In addition, we found that the addition of mineral powder would reduce the 3-day compressive strength of UHPC. Especially when the content of mineral powder was more than $25 \%$, the early strength of concrete decreased from 71.0 to 63.6 $\mathrm{MPa}$. At the 28th day, when the dosage of mineral powder increased from 10 to $20 \%$, the compressive strength of UHPC reached the maximum value, and the strength reached $103.6 \mathrm{MPa}$. It is not difficult to see whether adding mineral powder alone would significantly improve the compressive strength of UHPC. However, when mixed with silica fume, slag would enhance the 
TABLE 6 | Compressive strength of UHPC (M-PCE).

\begin{tabular}{lcccc}
\hline Number & \multicolumn{4}{c}{ Compressive strength (MPa) } \\
\cline { 2 - 5 } & 3d & $\mathbf{7 d}$ & $\mathbf{1 4 d}$ & $\mathbf{2 8 d}$ \\
\hline N1 & 71.6 & 76.9 & 87.3 & 92.5 \\
N2 & 74.5 & 82.8 & 96.8 & 117.4 \\
N3 & 70.0 & 79.3 & 86.6 & 94.6 \\
N4 & 66.7 & 80.0 & 93.5 & 109.4 \\
N5 & 71.2 & 83.8 & 90.6 & 97.4 \\
N6 & 70.9 & 82.7 & 98.3 & 108.5 \\
N7 & 64.7 & 73.6 & 86.2 & 93.3 \\
\hline
\end{tabular}

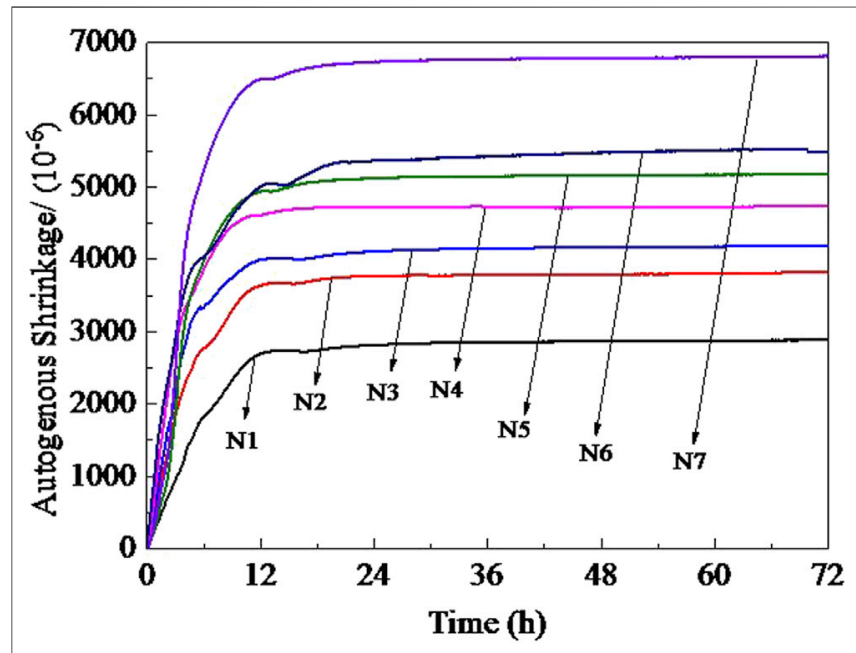

FIGURE 6 | Effect of M-PCE on auto-shrinkage of UHPC.

compressive strength of UHPC. According to previous studies, to improve the strength of concrete, the best constitution of cementitious materials is mainly associated with the calcium-tosilicon ratio (Erdem and Kirca, 2008; Elahi et al., 2010). When the calcium-to-silicon ratio is 1.30 , the strength of UHPC is greater than that of silica fume (Taylor, 1997).

\section{Drying Shrinkage}

Under the cement mortar-silica fume-mineral powder gelatinization system, M-PCE and Sika polycarboxylate, respectively, were adopted to prepare UHPC. The drying shrinkage changes of UHPC are shown in Figures 4, 5.

As shown in Figures 4, 5, UHPC prepared with M-PCE had slightly higher drying shrinkage as compared with UHPC prepared with Sika. Sika as a compound product has stronger capacity of reducing the surface tension of pore solution, so UHPC prepared with Sika will have a smaller drying shrinkage value.

Figures 4, 5 show that the drying shrinkage value of UHPC was the smallest when the dose of mineral powder was about $50 \%$. In addition, the drying shrinkage of UHPC increased with the addition of silica fume (N2 and N5 curves) because silica fume has high activity and can react with the hydration product $\mathrm{Ca}(\mathrm{OH})_{2}$ to form CSH gel (Yazıc1, 2007). Theoretically, there is a positive correlation between the degree of pozzolanic reaction

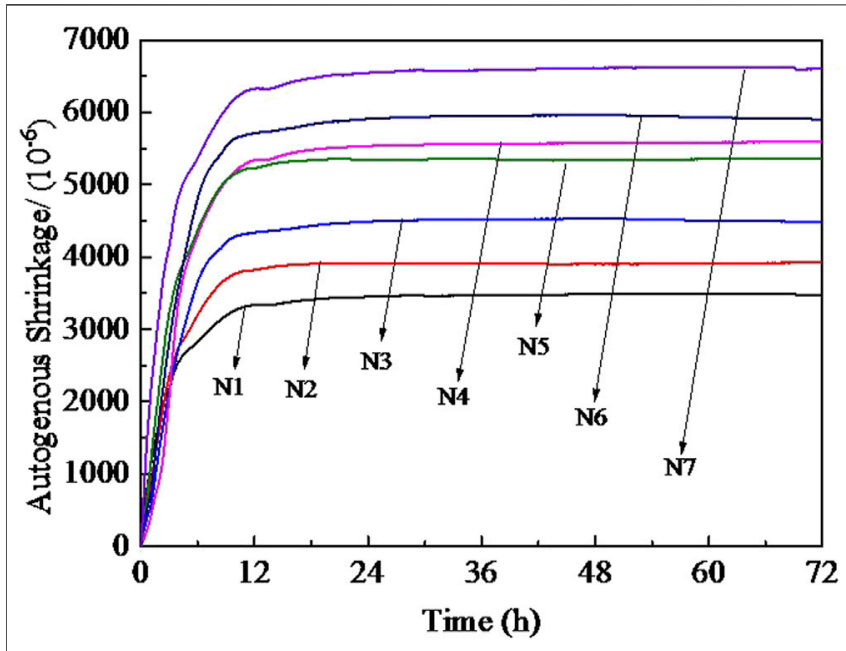

FIGURE 7 | Effect of Sika on auto-shrinkage of UHPC.

and the dose of silica fume. As a consequence, the dose of silica fume will increase the shrinkage value of UHPC (Zhang et al., 2003; Hong and Glasser, 2004).

\section{Auto-Shrinkage}

M-PCE and Sika polycarboxylates were, respectively, used to prepare UHPC. The auto-shrinkage changes of UHPC are shown in Figures 6, 7.

According to Figures 6, 7, under the same conditions, the influence of M-PCE on the auto-shrinkage of UHPC was similar to that of Sika. The auto-shrinkage of UHPC prepared with M-PCE or Sika is relatively smaller than that of UHPC prepared with pure Portland cement.

In addition, it was observed that the dosage of silica fume decreased the auto-shrinkage of UHPC (as shown in Figures 6, 7). In Figure 6, the content of silica fume increases from 15 to $30 \%$ and the auto-shrinkage ranges from 3,800 to 5,400 . In contrast, in Figure 7, this value ranges from 3,700 to 5,500 , which is consistent with reference (Duan et al., 2020), mainly due to the fact that the silica fume has large fineness, exerting special filling on the pore structure of cement-based materials. With the increasing dosage of silica fume, the capillary diameter will be reduced, causing greater capillary pressure and greater auto-shrinkage of UHPC (Rong et al., 2014).

In Figure 6, the content of mineral powder increases from 25 to $50 \%$ and its auto-shrinkage ranges from 4,200 to 6,800 . In Figure 7, the auto-shrinkage ranges from 4,400 to 6,600 . From the point of view of mineral powder, the auto-shrinkage of UHPC is also greatly affected by single addition. The pozzolanic activity and hydration degree of mineral powder were higher than those of Portland cement, leading to accelerated speed of water consumption and faster internal drying process (He et al., 2019).

\section{CONCLUSION}

In this study, polyurethane-modified polycarboxylate was synthesized at indoor temperature and its applications in 
UHPC, including water reduction rate of mortar, flowability, strength, drying shrinkage, and autogenous shrinkage, were investigated. The following conclusions were obtained based on the above experimental results and discussion:

(1) Because of the better compatibility with Portland cement of polyorganosiloxane in its molecular structure, M-PCE had better flowability and better dispersibility than the Sika superplasticizer.

(2) As far as compressive strength is concerned, UHPC prepared with M-PCE and Sika shows similar compressive strength. With the silica fume content ranging from 0 to $15 \%$, the compressive strength of concrete rose from 92.5 to 117.4 MPa (28 days). Addition of mineral powder would reduce the compressive strength of UHPC (3 days). Especially when the content of mineral powder was more than $25 \%$, the early compressive strength of concrete would decrease from 71.0 to $63.6 \mathrm{MPa}$, indicating that the compressive strength of UHPC was enhanced by adding silica fume but negatively affected by mineral powder.

(3) There is a negative relation between the dosage of mineral powder and silica fume and the drying shrinkage of UHPC. The larger the dosage of mineral powder is, the more obvious the decrease of drying shrinkage of UHPC is. However, the dosage of either mineral powder or silica fume may enhance its auto-shrinkage. The greater the dosage of mineral powder is, the greater the auto-shrinkage of UHPC is.

\section{REFERENCES}

Aitcin, P. C. (2003). The Durability Characteristics of High Performance Con- crete: Review [J]. Cem Concr Compos. 25, 409-420. doi:10.1016/S0958-9465(02)00081-1 Andersen, P. J., Roy, D. M., Gaidis, J. M., and Grace \& Co.fnm, W. R. (1987). The Effects of Adsorption of Superplasticizers on the Surface of Cement. Cement Concrete Res. 17 (5), 805-813. doi:10.1016/0008-8846(87)90043-3

Duan, K., Gao, Y., Yao, H., Zeng, W., Xu, Y., Zhou, W., et al. (2020). Comparison of Performances of Early Aged Pre-vibrated Cement-Stabilized Macadam Formed by Different Compactions. Construction Building Mater. 239, 117682. doi:10.1016/j.conbuildmat.2019.117682

Duval, R., and Kadri, E. H. (1998). Influence of Silica Fume on the Workability and the Compressive Strength of High-Performance Concretes. Cement Concrete Res. 28 (4), 533-547. doi:10.1016/s0008-8846(98)00010-6

Elahi, A., Basheer, P. A. M., Nanukuttan, S. V., and Khan, Q. U. Z. (2010). Mechanical and Durability Properties of High Performance Concretes Containing Supplementary Cementitious Materials. Construction Building Mater. 24, 292-299. doi:10.1016/j.conbuildmat.2009.08.045

Erdem, T. K., and Kırca, Ö. (2008). Use of Binary and Ternary Blends in High Strength concrete. Construction Building Mater. 22, 1477-1483. doi:10.1016/ j.conbuildmat.2007.03.026

Ganesh, B. K., and Surya, P. P. V. (1995). Efficiency of Silica Fume in concrete. Cement Concrete Res. 25 (6), 1273-1283. doi:10.1016/0008-8846(95)00120-2

He, B., Gao, Y., Qu, L., Duan, K., Zhou, W., and Pei, G. (2019). Characteristics Analysis of Self-Luminescent Cement-Based Composite Materials with SelfCleaning Effect. J. Clean. Prod. 225, 1169-1183. doi:10.1016/ j.jclepro.2019.03.291

Hong, S.-Y., and Glasser, F. P. (2004). Phase Relations in the CaO-SiO2-H2o System to $200{ }^{\circ} \mathrm{C}$ at Saturated Steam Pressure. Cement Concrete Res. 34 (9), 1529-1534. doi:10.1016/j.cemconres.2003.08.009

Jones, M., Dhir, R., and Gill, J. (1995). Concrete Surface Treatment: Effect of Exposure Temperature on Chloride Diffusion Resistance. Cement Concrete Res. 25 (1), 197-208. doi:10.1016/0008-8846(94)00127-k

\section{DATA AVAILABILITY STATEMENT}

The original contributions presented in the study are included in the article/Supplementary Material, and further inquiries can be directed to the corresponding author.

\section{AUTHOR CONTRIBUTIONS}

SX conceptualized the study, was responsible for the methodology, investigated the data, performed data curation and formal analysis, and wrote the original draft. YG was involved in project administration, funding acquisition, and supervision. YT revised the manuscript.

\section{ACKNOWLEDGMENTS}

The authors gratefully acknowledge the financial support from National Natural Science Foundation of China and Civil Aviation Administration of China (U1833127), National Key R\&D Program of China (Grant Number: 2018YFB1600100), National Natural Science Foundation of China (General Program: 51978080), Natural Science Foundation of Hunan Province(2021JJ40602) and Scientific Research Project of Hunan Provincial Department of Education(20B014).

Kagi, D. A., and Ren, K. B. (1995). Reduction of Water Absorption in Silicate Treated concrete by post-treatment with Cationic Surfactants. Building Environ. 30 (2), 237-243. doi:10.1016/0360-1323(94)00047-v

Khatri, R. P., Sirivivatnanon, V., and Gross, W. (1995). Effect of Different Supplementary Cementitious Materials on Mechanical Properties of High Performance concrete. Cement Concrete Res. 25 (1), 209-220. doi:10.1016/ 0008-8846(94)00128-1

Khayat, K. H., and Aitcin, P. C. (1993). "Silica Fume: a Unique Supplementary Cementitious Material," in Mineral Admixtures in Cement and concrete. Editor S. N. Ghosh (New Delhi, India: ABI Books Private Limited), 227-265.

Levi, M., Ferro, C., Regazzoli, D., Dotelli, G., and Lo presti, A. (2002). Comparative Evaluation Method of Polymer Surface Treatments Applied on High Performance concrete. J. Mater. Sci. 37 (22), 4881-4888. doi:10.1023/a: 1020810113110

Li, C. Z., Feng, N. Q., Li, Y. D., and Chen, R. J. (2005). Effects of Polyethlene Oxide Chains on the Performance of Polycarboxylate-type Water-Reducers. Cement Concrete Res. 35 (5), 867-873. doi:10.1016/j.cemconres.2004.04.031

Mazloom, M., Ramezanianpour, A. A., and Brooks, J. J. (2004). Effect of Silica Fume on Mechanical Properties of High-Strength concrete. Cement and Concrete Composites 26 (4), 347-357. doi:10.1016/s0958-9465(03)00017-9

Rong, Z. D., Sun, W., Xiao, H. J., and Wang, W. (2014). Effect of Silica Fume and Fly Ash on Hydration and Microstructure Evolution of Cement Based Composites at Low Water-Binder Ratios. Construction Building Mater. 51, 446-450. doi:10.1016/j.conbuildmat.2013.11.023

Shang, Y., Miao, C. W., Liu, J. P., and Ran, Q. P. (2009). New Build Mater. (In Chinese) 12 (4), 12-14.

Shi, C. J., and He, F. Q. (2010). "Properties and Microstructure of $\mathrm{CO}_{2}$ Cured concrete Blocks," in Proceedings of the 2nd International Conference on Waste Engineering and Management, Shanghai, China, October 13-15,2010, 96-107.

Shi, C. J. (2009). "Recent Development of PC Superplasticizers [C]," in Proceedings of the 2nd International Symposium on Mix Design, Performance and Use of SCC, Beijing, June 5-7, 2009, 16-25.

Taylor, H. F. W. (1997). Cement Chemistry. London, England: Thomas Telford Services Ltd. doi:10.1680/cc.25929 
Thompson, J. L., Silsbee, M. R., Gill, P. M., and Scheetz, B. E. (1997). Characterization of Silicate Sealers on concrete. Cement concrete Res. 27 (10), 1561-1567. doi:10.1016/s0008-8846(97)00167-1

Yazıc1, H. (2007). The Effect of Curing Conditions on Compressive Strength of Ultra High Performance concrete with High Volume mineral Admixtures. Building Environ. 42, 2083-2089. doi:10.1016/j.buildenv.2006.03.013

Zhang, M. H., Tam, C. T., and Leow, M. P. (2003). Effect of Water-To-Cementitious Materials Ratio and Silica Fume on the Autogenous Shrinkage of concrete. Cement Concrete Res. 33 (10), 1687-1694. doi:10.1016/s0008-8846(03)00149-2

Conflict of Interest: The authors declare that the research was conducted in the absence of any commercial or financial relationships that could be construed as a potential conflict of interest.
Publisher's Note: All claims expressed in this article are solely those of the authors and do not necessarily represent those of their affiliated organizations, or those of the publisher, the editors and the reviewers. Any product that may be evaluated in this article, or claim that may be made by its manufacturer, is not guaranteed or endorsed by the publisher.

Copyright $\odot 2021$ Xiang, Tan and Gao. This is an open-access article distributed under the terms of the Creative Commons Attribution License (CC BY). The use, distribution or reproduction in other forums is permitted, provided the original author(s) and the copyright owner(s) are credited and that the original publication in this journal is cited, in accordance with accepted academic practice. No use, distribution or reproduction is permitted which does not comply with these terms. 